\title{
Neck Stiffness
}

National Cancer Institute

\section{Source}

National Cancer Institute. Neck Stiffness. NCI Thesaurus. Code C50664.

Limited mobility of the neck, usually accompanied by pain. 